\title{
Nodule Shape
}

National Cancer Institute

\section{Source}

National Cancer Institute. Nodule Shape. NCI Thesaurus. Code C157673.

A description about the radiologic shape of a nodule. 